\title{
Empreendedorismo, infância e celebridades: análise dos discursos do empreendedorismo para crianças $^{1}$
}

\author{
Vander Casaqui \\ Doutor; Universidade Metodista de São Paulo, São Bernardo do Campo, SP, Brasil \\ vcasaqui@yahoo.com.br
}

\section{Fernando Matijewitsch}

Mestre; Escola Superior de Propaganda e Marketing, São Paulo, SP, Brasil

fernando.matijewitsch@gmail.com

\section{Camila Brandão Simurro Figueiredo}

Mestra; Escola Superior de Propaganda e Marketing, São Paulo, SP, Brasil

figueiredo.camila@gmail.com

\section{Resumo}

Este artigo tem como tema a cultura empreendedora, que corresponde a um processo para além da atividade econômica: refere-se às práticas sociais, aos perfis comportamentais, às prescrições morais e ao mercado de ideias em torno do empreendedor como modelo paradigmático de nosso tempo. Nesse espectro, tratamos da intersecção entre o empreendedorismo e dois outros temas: a infância e as celebridades, a partir da análise dos discursos do empreendedorismo voltado às crianças. O quadro teórico que organiza nossa reflexão baseia-se nas teses de Dardot e Laval sobre a sociedade neoliberal; na teoria do novo espírito do capitalismo de Boltanski e Chiapello; em obras fundamentais da discussão sobre infância e celebridades, entre outras. A metodologia de análise do corpus é baseada na proposta teórico-metodológica da análise do discurso social.

\section{Palavras-chave}

Comunicação. Cultura empreendedora. Infância. Celebridades. Discurso.

\footnotetext{
1 Versão modificada de artigo apresentado no IV Seminário de Pesquisa da Fundação Escola de Sociologia e Política de São Paulo (FESPSP) 2017: As Incertezas do Trabalho, realizado entre os dias 2 e 5 de outubro de 2017, no campus da FESPSP, na cidade de São Paulo.
} 


\section{Introdução}

O tema do empreendedorismo é recorrente no contexto contemporâneo: ao passo que o termo populariza-se, seu campo semântico é ampliado e passa a abarcar as mais diversas esferas de atuação humana. Da relação óbvia com o mundo do trabalho à vida cotidiana de forma ampla, a noção de empreender compreende desde a questão específica de montar um negócio próprio até a interpelação dos indivíduos, que são convocados a transformarem-se, a produzirem-se de acordo com o paradigma do ideal empresarial de si (SAFATLE, 2015) em todas as facetas da existência.

Nesse espectro, não é de estranhar-se que o período da infância seja visado por discursos presentes na cena midiática, como as narrativas de vida exemplares (BUONANNO, 2011) - trajetórias modelos de sucesso para inspirar as crianças a seguirem o caminho da cultura empreendedora desde cedo. A noção de inspiração, nesse contexto, é um elemento importante que revela o desejo de cooptar o outro para tomar parte nesse projeto de sociedade, a sociedade empreendedora. A inspiração caracteriza a intencionalidade comunicacional desse projeto, pois está associada à função de propagar a sua visão de mundo e estimular o mimetismo de seus modelos de conduta. Daí a importância de observar como as crianças são enquadradas pelos discursos que estão articulados ao empreendedorismo.

Este trabalho discute criticamente a cultura empreendedora contemporânea, entendida enquanto processo comunicacional, por meio da investigação de discursos que disseminam os preceitos do empreendedorismo na teia social, em cadeias complexas de produção, circulação e consumo. Para atender ao objetivo de pesquisa de compreender como esses discursos constituem um código hegemônico na atualidade, que inclui a infância em sua edição de mundo, adotamos a perspectiva de análise do discurso social proposta por Marc Angenot (2010). Para o autor, a hegemonia é "[...] um sistema regulador que predetermina a produção de formas discursivas concretas." (ANGENOT, 2010, p. 30, tradução nossa). 0 discurso social corresponde a essa concretude linguística, que envolve “[...] os sistemas genéricos, os repertórios tópicos e as regras de encadeamento de enunciados que, em uma dada sociedade, organizam o dizível - o narrável e opinável - e asseguram a divisão do trabalho discursivo." (ANGENOT, 2010, p. 21, tradução nossa). 
A proposta de Angenot (2010) é baseada na filosofia da linguagem de Mikhail Bakhtin; a perspectiva dialógica é aplicada à leitura do discurso social. Dessa forma, os enunciados são compreendidos como elos de cadeias discursivas que são atravessados por “"[..] visões de mundo, tendências, teorias' de uma época." (ANGENOT, 2010, p. 25). As noções de intertextualidade "[...] como circulação e transformação de ideologemas, quer dizer, de pequenas unidades significantes [...]" (ANGENOT, 2010, p. 25), bem como de interdiscursividade, entendida como a interação e interinfluência dos discursos, são centrais para a missão de identificar as características de um discurso social - que está longe de ser universal, mas que, ao mesmo tempo, delimita historicamente o horizonte do que é pensável e dizível.

Defendemos que o empreendedorismo corresponde a essa noção de discurso social definida por Angenot (2010), porque traduz o espírito de um tempo e impõe-se como ideologia, sobrepõe-se ao mundo do trabalho, flerta com a infância e agrega valores desejáveis na sociedade, que se disseminam por um sem número de agentes, marcando sua onipresença na cena midiática, em planos educacionais e em projetos de futuro.

A fim de compreendermos este fenômeno, que alcançou até a infância (BUCKINGHAM, 2007), elegemos como objeto de análise os discursos de duas celebridades infantis, a saber: Kylee Majkowski e Davizinho Braga, expoentes da cena empreendedora; e uma publicação voltada ao incentivo do empreendedorismo desde a infância, de outra celebridade relacionada a esse campo - trata-se da cartilha Aventuras da Bel, assinada por Bel Pesce (2015).

Kylee Majkowski reside nos arredores de Washington (EUA) com sua família e fundou a empresa Tomorrow's Lemonade Stand com apenas sete anos de idade. Seu objetivo é dar a crianças de sete a onze anos a oportunidade de criar um negócio próprio, assim como inspirar a criatividade, a tomada de riscos, a empatia e também o encontro de suas paixões. No 28ํㅜ Fórum da Liberdade, Kylee subiu ao palco no Painel Empreendedorismo e disse "[...] acreditar profundamente que 'pensar fora da caixa' vai ajudar a si mesma e a seus amigos a construir a vida que eles querem." (MAJKOWSKI, 2015, doc. não paginado). Seu discurso ecoa lugares comuns identificados com a cultura empreendedora, independentemente da peculiaridade de ser criança.

Davizinho Braga, por sua vez, mora com seus pais no estado brasileiro de Alagoas. Com 13 anos, criou a própria startup, a List-it, um site para que as escolas cadastrem sua lista de materiais e para que os pais adquiram esses objetos com mais facilidade. No ano 
seguinte, fez sua primeira palestra no TEDx Talks, onde contou a história de sua vida e os segredos de sua felicidade: família, vontade, raciocínio, coragem e sonhos foram alguns dos tópicos abordados por ele (BRAGA, 2015).

Por fim, Aventuras da Bel é uma história em quadrinhos que tem como protagonista Bel Pesce, mais conhecida como "a menina do Vale" - nome de seu primeiro livro autobiográfico, um sucesso de vendas do que denominamos autoajuda empreendedora. Segundo o site oficial da publicação, o propósito da obra Aventuras da Bel é “[...] ensinar através da diversão [ao representar em] [...] diversas situações do dia a dia que todos os sonhos podem virar realidade e que tudo é possível se você se dedicar de cabeça e coração."(PESCE, 2015, doc. não paginado).

O que unifica a seleção dos três objetos deste estudo é o objetivo de discutirmos as conexões entre empreendedorismo, a emergência de celebridades relativas a essa cena e a questão da infância como tema de discursos, palestras, publicações, entre outros elementos que compõem um verdadeiro mercado de ideias (ANGENOT, 2010). Esse mercado, por sua vez, tornou-se um setor econômico relevante, com diversos agentes capitalizando sua entrada na cena midiática em sua tarefa de disseminar a ideologia da sociedade neoliberal (DARDOT; LAVAL, 2016).

De maneira geral, este cenário afirma, de forma recorrente, a máxima de que todos podem e devem ser empreendedores, independentemente de qualquer barreira pessoal ou financeira (COSTA; SARAIVA, 2011). 0 "modelo de conduta" (EHRENBERG, 2010) a ser seguido é representado pelo ethos do indivíduo empreendedor, reforçando a ideia do empreendedorismo de si como qualidade essencial para se alcançar o sucesso. Juntamente com o sucesso, a felicidade é vista como um projeto individual decorrente da capacidade de empreender a si mesmo desde a infância. Tais discursos, como as palestras realizadas por Davizinho e Kylee no TEDx Talks e em fóruns voltados a negócios, por exemplo, acabam sustentando as lógicas de justificação do novo espírito do capitalismo (BOLTANSKI; CHIAPELLO, 2009) e auxiliam a tecer a noção de um projeto de sociedade baseado na monocultura empreendedora (CASAQUI, 2017) do qual nem as crianças podem ficar de fora.

\section{0 empreendedorismo como cultura e como mercado}

Em trabalhos anteriores (CASAQUI, 2016a, 2016b, 2017), abordamos o estudo do empreendedorismo como cultura, uma vez que ser empreendedor em nosso tempo é algo 
associado a uma atitude modelar, difundida por um sem número de agentes. Entender esse fenômeno como cultura é identificar a constituição de uma cena, com um amplo espectro de enunciadores e analistas simbólicos que falam em nome do campo do empreendedorismo: de instituições de incentivo e capacitação para a atividade empreendedora (como é o caso do Serviço Brasileiro de Apoio às Micro e Pequenas Empresas, Sebrae, e da Endeavor Brasil), passando pelos discursos presentes na cena midiática (como o programa Mundo $S / A$, do canal de TV por assinatura Globonews) e chegando às narrativas de autoajuda, como é o caso dos pacotes biopolíticos (PRADO, 2012) promovidos por celebridades empreendedoras (também chamados de empreendedores de palco), como Flávio Augusto (Blog Geração de Valor) e Bel Pesce.

O que há de comum nessa diversidade de agentes é exatamente a missão de publicizar, de difundir o modelo de conduta empreendedor como positivo, desejável e até como via única para o futuro dos indivíduos, das cidades, dos países, do mundo. Essa perspectiva de futuro é ancorada, entre outras abordagens, na inclusão das crianças como seres a serem preparados para a idade adulta, tendo como norteadora de seu desenvolvimento uma espécie de educação empreendedora. Esse princípio educacional, para além da escola, está baseado numa pedagogia que se configura a partir de processos comunicacionais, os quais dão visibilidade a "histórias de vida exemplares", como defende Buonanno (2011). Aprender com o exemplo, com a prática, com as narrativas de sucesso e de felicidade: essa é a perspectiva da pedagogia empreendedora, que guarda parentesco próximo com a cultura da autoajuda, como defende Marín-Diaz (2012, p. 19): "Os discursos de autoajuda são considerados como discursos pedagógicos, porque são usados para modificar a conduta dos indivíduos pela ação que cada um realiza sobre si mesmo".

Defendemos, em alinhamento com a autora, que os discursos que promovem o empreendedorismo para crianças estão associados a uma “[...] preocupação pelo governo de si e dos outros [que] se encontra no âmago da constituição de um campo de saberes, noções, conceitos e práticas relativas à educação e à pedagogia [...]" (MARÍN-DIAZ, 2012, p. 19). A promoção da ideia de que a criança pode e, mais que isso, deve ser preparada para empreender desde cedo está baseada numa lógica da governamentalidade foucaultiana; a infância seria mais um produto da "fábrica do sujeito neoliberal", como definem Dardot e Laval (2016). Como elemento-chave dessa proposta de produção dos "empreendedores do futuro", a estratégia de interpelação da criança serve a um projeto comunicacional da sociedade empreendedora. Como pressuposto para a legitimação e a justificação dessa 
interpelação, há uma espécie de salvo conduto moral, difundido por essa cultura, para os sujeitos empreendedores. Eis a ideologia da "gente de bem" que empreende em busca da felicidade, do sucesso, até do lucro, mas sempre com "propósito".

Nesse espectro, observamos com especial interesse a emergência e a celebrização de crianças que são identificadas como empreendedores de sucesso, como é o caso de Kylee Majkowski e Davizinho Braga, e de celebridades adultas do campo do empreendedorismo que produzem uma versão de si mesmas para as crianças, como é o caso da cartilha Aventuras da Bel.

\section{Aventuras da Bel e o conceito de infância}

Partimos da premissa de que a infância é uma concepção social. Segundo Buckingham (2007, p. 19), o argumento central a esse respeito é o “[...] de que 'a criança' não é uma categoria natural ou universal, determinada simplesmente pela biologia. Nem é algo que tenha um sentido fixo, em cujo nome se possa tranquilamente fazer reivindicações". Longe disso: a infância, na verdade, varia de acordo com a conjuntura levada em consideração. As crianças são contempladas - e contemplam a si mesmas - de maneiras muito diferentes nos mais variados períodos históricos, contextos culturais e grupos sociais. Além disso, o significado de infância está submetido a incessantes embates e negociações, tanto no discurso público (do qual a mídia, a academia e as políticas públicas fazem parte) como nos relacionamentos pessoais, entre familiares e colegas.

Seguindo o pensamento de Buckingham (2007), não sugerimos aqui que os seres biológicos a quem concordamos coletivamente em chamar de crianças não existam, ou não possam ser descritos. 0 que pretendemos é dizer que "[...] tais definições coletivas são o resultado de processos sociais e discursivos" (BUCKINGHAM, 2007, p. 20, grifo nosso). De acordo com o autor, a delimitação e a sustentação do conceito de infância dependem, de forma geral, da produção de dois tipos fundamentais de discurso. Em primeiro lugar, temos os discursos sobre a infância, elaborados por adultos e, prioritariamente, voltados para outros adultos - não só na forma dos discursos profissionais ou acadêmicos, mas também na forma de literatura popular de autoajuda, romances e programas de televisão. Em segundo lugar, existem os discursos para as crianças, que se apresentam na forma de programas voltados a determinadas mídias ou à literatura infantil. Apesar do rótulo, esse tipo de 
discurso é raramente criado e elaborado pelas próprias crianças. Aventuras da Bel Pesce é um produto cultural que se encaixa perfeitamente no segundo tipo.

No site da publicação, encontramos apenas duas histórias em quadrinhos (HQs), porém Aventuras da Bel Pesce: perdidos na selva é a única que possui uma construção narrativa. Nessa publicação, que possui 19 páginas ao todo, Bel Pesce explica como ela e sua turma conseguiram solucionar os problemas que apareceram durante um passeio ecológico (PESCE, 2015).

No decorrer de toda $\mathrm{HQ}$, a autora apresenta os personagens de forma didática e representativa; é possível observar que cada criança representa um tipo social associado ao mundo do trabalho e caracterizado como um comportamento unificado, como se fossem sentimentos traduzidos em personagens. Entendemos essa personificação como uma estratégia discursiva e pedagógica para enfatizar as características positivas e negativas que as crianças devem, ou não, levar para suas vidas.

É identificável, de imediato, que a escolha dos nomes é vinculada à personalidade estereotipada de cada personagem. Ou seja, o nome de cada criança, na história, possui uma carga de significado, correspondendo a um campo semântico evocado pela nominalização. 0 nome Estela parece nos remeter à palavra estrela: uma mulher bonita, chamativa, que se preocupa bastante com a visibilidade e o visual; Tanura remete-nos também à palavra ternura, atributo identificado ao longo da $\mathrm{HQ}$, quando a personagem mostra sua paciência e trato com os colegas. Já Fly - fly é uma palavra inglesa que significa voar - é um personagem com uma espécie de déficit de atenção, que passa a maior parte do tempo com seus fones de ouvido, interagindo com tecnologias digitais.

Curiosamente, o robô da turma é nomeado de Chiste. Tal termo estabelece uma relação direta com um conceito freudiano - a palavra é originada do alemão Witz, que significa gracejo. Na obra $O$ chiste e sua relação com o inconsciente, o psicanalista investiga as fontes inconscientes do prazer, que nos afetam quando estamos frente a gracejos, piadas, trocadilhos e ironias (MACEDO; FALCÃO, 2005).

Ao longo da HQ, percebemos que Chiste possui sentimentos expressos em forma de humor, mas é curioso observar que, embora seja uma máquina, nunca aponta um cálculo correto por ser muito desajeitado. Em forma de robô, ele é a figurativização do capital humano - é a cópia mal feita do ser humano e possui uma falha gravíssima: falta de inteligência emocional. Aqui, as emoções são vistas como patologia, algo a ser racionalizado nas interações em grupo, principalmente quando relacionadas ao trabalho. A marca 
intertextual que nos remete aos manuais de psicologia positiva - os quais pregam a necessidade da gestão racional dos afetos - faz-se presente na tradução da noção de capital humano para o gênero das histórias em quadrinhos. Intertextualidade e interdiscursividade operam na adaptação dos preceitos do empreendedorismo para o universo infantil.

Esse tipo de falta ou defeito pode ser observado em todos os personagens: Analu é muito tímida; Lila é curiosa em excesso; Estela é superficial demais; Tanura só consegue enxergar soluções calculáveis; Fly não possui o poder da concentração; Tatau é um menino popular, com certa arrogância, sem nunca ter feito nenhum tipo de contribuição significativa; Pirote é pessimista e Egoberto, como seu próprio nome revela, é egocêntrico e acredita que sabe de tudo. Nessa construção de personagens, há uma simulação de dialogismo, uma orquestração de vozes que representaria a teia social em sua diversidade, mas que é constituída em pleno alinhamento com os preceitos da cultura empreendedora que a história objetiva difundir.

Nesse sentido, os defeitos dos personagens só são ressaltados porque possuem uma solução. Bel é a líder do grupo e, como líder visionária, consegue identificar tais atributos e corrigi-los de uma vez por todas. Dessa maneira, o objetivo de Bel é consagrado: unir essas crianças e fazê-las trabalhar em grupo, consertando seus defeitos. Isso é visível ao observarmos o quadrinho abaixo (Figura 1):

Figura 1 - Reunião de emergência em Aventuras da Bel

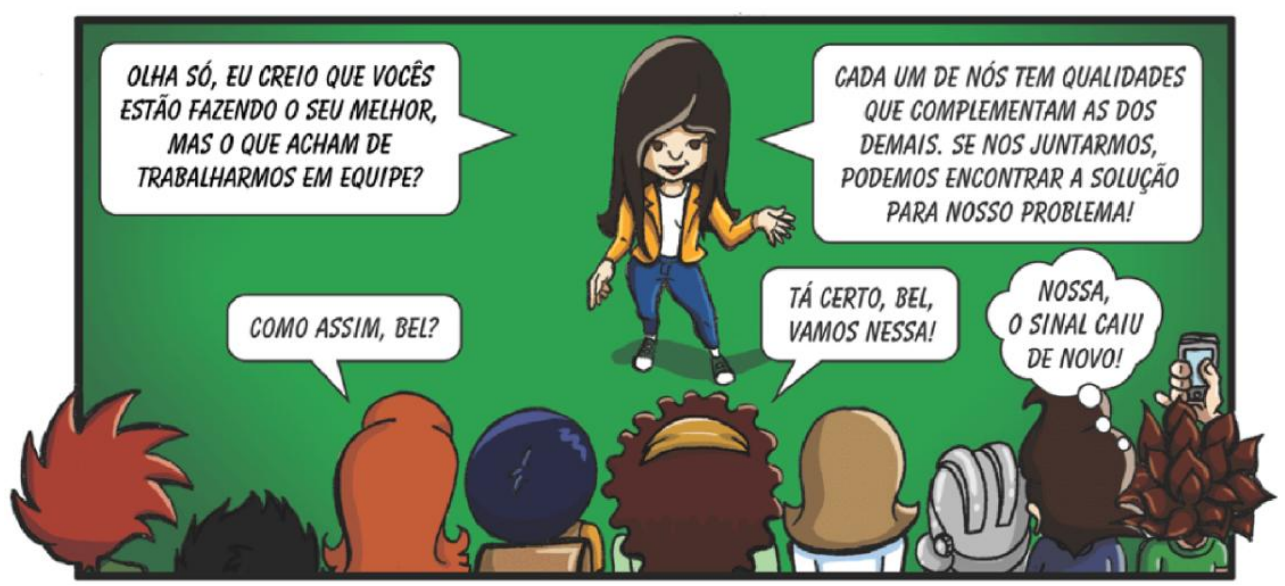

Fonte: Pesce (2015).

Depois de perderem a bússola que os levaria de volta para casa, o grupo inteiro fica em completo desespero, o que faz Bel começar uma reunião de emergência antes que a 
angústia tomasse conta de todos. A fim de trazer o interlocutor para a história, o leitor acaba sendo um personagem da cena. Com a composição do quadro - com todas as crianças na parte inferior, de costas ao olhar do leitor - a impressão que fica é que esta é a primeira fileira de um grande anfiteatro lotado para ouvir e aprender com Bel Pesce. Isto também é evidenciado pela perspectiva utilizada na cena: a protagonista tem todo o quadro para si e encontra-se no centro, como se realmente estivesse num palco.

Além da posição de destaque no quadro, a empresária veste uma roupa que geralmente é associada à vestimenta típica de palestrantes do mundo dos negócios. Nesse contexto, Bel Pesce é representada como uma líder nata e pronta para conciliar as diferenças do grupo e tentar resolver o problema que se manifestou. Mais interessante ainda é a postura da personagem e o movimento aparente de seus braços. A serenidade em seu rosto representa a calma de uma pessoa que está na posição de ensinar um grupo de crianças - inclusive o leitor - a lidar com situações de dificuldade. Seus gestos acompanham essa postura pedagógica.

Essa HQ se estabelece como mais um elo na cadeia dos discursos do empreendedorismo e pode ser considerada como uma adequação específica desse universo voltada à infância - como uma tradução dos códigos hegemônicos mobilizados pela cultura empreendedora. O texto de Aventuras da Bel, assim como o de outras obras similares, demonstra esforço em educar, dar lições de moral e, dessa maneira, apresentar os modelos de comportamento vistos como desejáveis socialmente (BUCKINGHAM, 2007). Como nos diz Postman (2012, p. 78), "[...] ao dizermos o que queremos que uma criança venha a ser, dizemos o que somos".

Diante de um projeto de sociedade que propaga o ideário da cultura empreendedora para todos, atentamos para a disseminação crescente de instruções para a prática do empreendedorismo direcionadas ao público infantil. Entre si, compartilham o objetivo de transmitir a atitude de liderança, a criatividade inovadora e os métodos para a abertura de novos negócios - visam, enfim, a introjetar o "espírito" empreendedor, com todos os seus pressupostos comportamentais e morais, desde as origens no futuro adulto. Observamos que a forma pedagógica para a construção de uma infância empreendedora é baseada em narrativas inspiracionais. A inspiração é o objetivo transcendente para a intencionalidade de convocar os indivíduos, neste caso, as crianças, a tomar parte nesse projeto de sociedade empreendedora. 
Em Aventuras da Bel, por exemplo, a metáfora da bússola apresenta um significado muito forte: o único jeito de sair da "selva" seria utilizando a "bússola" do empreendedorismo. Bel, então, reúne as crianças, no final da história, para construir uma bússola com as próprias mãos e, assim, conseguir voltar à civilização. Ela tem, aqui, o papel do líder inspirador, que está ali para ensinar à sua audiência o caminho correto, baseado na ideologia da cultura maker, ou seja, da "gente que faz", que produz, que empreende seus caminhos e seu futuro. A felicidade e o sucesso são vistos, nesse contexto, como projetos individuais decorrentes da capacidade de empreender a si mesmo desde a infância. 0 espectro do dizível em relação à infância ajusta-se ao modelo paradigmático do empreendedorismo de nosso tempo, o horizonte histórico ao qual a criança é projetada.

\section{Kylee Majkowski e o direito de nascer empreendedor}

Para Paul Hollander (2011), a mídia é um campo de validação existencial; estar na mídia torna um indivíduo - e o que ele diz, faz ou representa - digno de atenção. No âmbito de nossa pesquisa, o conceito de celebridade aproxima-se e está interligado com o conceito de self made man: ou seja, alguém que alcançou o sucesso e tornou-se um modelo, um ícone dos valores importantes para a sociedade capitalista, tendo como motor sua personalidade, isto é, apenas a si mesmo. Nesse sentido, a busca por uma trajetória bem sucedida, inspirada na história de vida do outro, tornou-se algo comum e, por isso, as narrativas de vida autobiográficas e biográficas ganharam tanto destaque na cena empreendedora. Isso porque esses sujeitos modelos passam a representar mais do que seus papéis na esfera econômica; são exemplos de comportamento e normas para a sociedade por meio de seus discursos e histórias de vida exemplares. Esse interesse alimenta um verdadeiro mercado de ideias (ANGENOT, 2010), que, por sua vez, dá sustentação a práticas de consumo em torno do tema do empreendedorismo, como livros, palestras, cursos à distância, entre outras materialidades.

0 processo de celebrização estimula, ainda, o culto à personalidade: "O valor da exibição migra dos feitos e obras para o próprio eu. É preciso se mostrar, é preciso 'ser' publicamente." (FRANÇA, 2014, p. 31). Tais ídolos celebrizados são "modelos de conduta" (EHRENBERG, 2010) que devem ser seguidos no âmbito comportamental, estilístico, estético e até mesmo político ou religioso. Isso porque eles representam a trajetória possível 
para alcançar a felicidade e o sucesso. Assim, a pessoa dita comum, ao identificar-se com o modo de ser da celebridade, inspira sua própria existência.

Nesse sentido, duas figuras surgem como sendo de especial interesse para nosso estudo. Kylee Majkowski e Davizinho Braga podem ser considerados celebridades empreendedoras, uma vez que trazem suas trajetórias de sucesso como exemplares para inspirar as crianças a seguirem o caminho do empreendedorismo desde cedo. 0 interessante é que ambos fazem isso em espaços midiáticos voltados essencialmente para o público adulto.

Em abril de 2015, Kylee Majkowski subiu ao palco do 28o Fórum da Liberdade (Figura 2), com sede em Porto Alegre (RS), e palestrou durante o Painel Empreendedorismo oferecido pelo evento (MAJKOWSKI, 2015). Ao narrativizar sua história de vida com o objetivo de inspirar seus ouvintes, a garota norte-americana insere-se na construção de um mercado de ideias associado ao que denominamos de "cultura da inspiração" (CASAQUI, 2017). A relação entre esse tipo de produção comunicacional e o empreendedorismo dirigese "[...] para certa recorrência de formas de articular a experiência humana com um 'espírito', com uma visão de mundo, que, em última instância, promove, direta ou indiretamente, a ideia de uma comunidade de práticas e afetos comuns." (CASAQUI, 2017, p. 4). Nesse sentido, os enunciadores vistos como inspiradores atuam como sistemas especialistas (GIDDENS, 2002), compartilhando o objetivo de "[...] corresponder aos anseios de uma sociedade ávida por referências, por modelos, por exemplos e histórias 'inspiradores' para seguir adiante na batalha cotidiana." (CASAQUI, 2017, p. 4).

Figura 2 - Kylee Majkowski na 28ae edição do Fórum da Liberdade

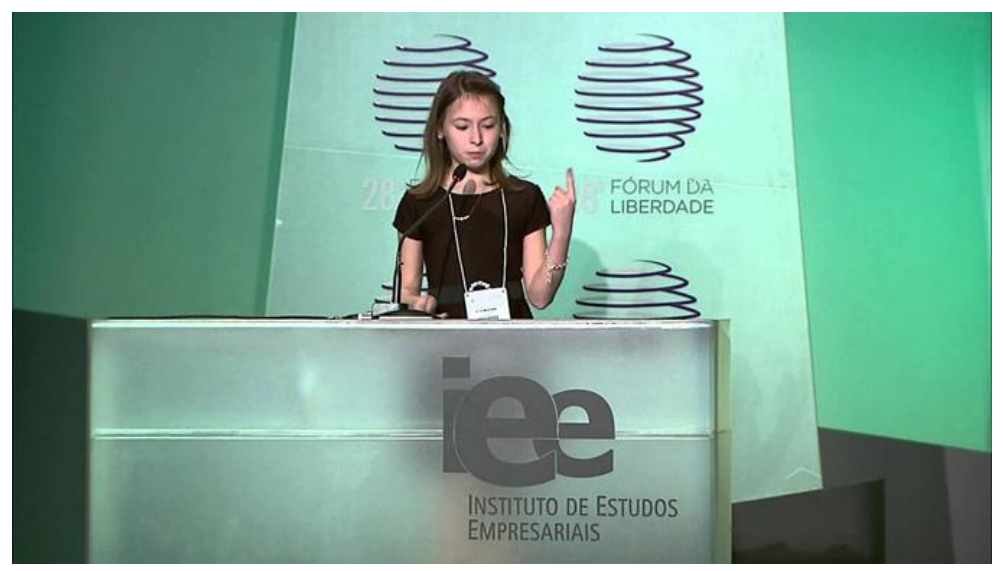

Fonte: Majkowski (2015). 
Kylee começa sua palestra com a seguinte máxima: "As crianças podem fazer qualquer coisa que os adultos fazem[...]" (MAJKOWSKI, 2015). Com essa fala, que ganha ares de discurso competente ao ser identificado com uma criança celebrizada como empreendedora, a palestrante ressalta o pensamento controverso que afirma haver na contemporaneidade: uma atenuação ou mesmo desaparição das linhas fronteiriças entre o mundo adulto e o mundo das crianças (POSTMAN, 2012). Esse tipo de discurso prevê a criança como um adulto em miniatura, pronto para encarar qualquer tipo de responsabilidade e consequência dos seus atos no mercado de trabalho.

Dessa maneira, Kylee defende veementemente a educação utilitária. Ao questionar, durante a palestra, o motivo que leva meninos e meninas a aprenderem História, Geografia e outras disciplinas na escola, em detrimento de práticas empreendedoras, a palestrante encara a educação apenas como um mecanismo para passar adiante as técnicas de um determinado saber fazer, de um determinado saber ser. Assim, a noção de educação é apartada definitivamente de seu caráter possível de promotora da autonomia, sendo atravessada por um aglomerado de práticas de aperfeiçoamento cujo fim é governar subjetividades e produzir formas de vida específicas, apropriadas ao projeto de sociedade empreendedora.

Para Marín-Díaz (2012), podemos pensar as práticas pedagógicas, enquanto atividades prescritas com o objetivo de formar e definir modos de comportamento, como técnicas de condução ou de governo. "Isso porque nessas práticas são incorporados e desenvolvidos exercícios destinados à transformação do indivíduo, com o propósito de leválo a se enquadrar nos modos de vida de seu grupo social" (MARÍN-DIAZ, 2012, p. 37). Nesse sentido, a narrativa de Kylee estabelece relação com os discursos de autoajuda, que, para a autora, têm uma função pedagógica nos termos da convocação para a autotransformação.

Como visto, ser empreendedor em nossa sociedade não é uma ação que precisa obrigatoriamente estar conectada à concepção de um novo negócio ou a uma atividade econômica. Refere-se, antes de qualquer coisa, a um conjunto de regras de comportamento que serve de norteador aos indivíduos nos diversos campos de suas vidas. Nesse sentido, é interessante observar qual é o primeiro trabalho que a Tomorrow's Lemonade Stand desenvolve com as crianças que desejam tornar-se empreendedoras. Nas palavras de Kylee, "o básico do empreendedorismo", que deve ser o primeiro contato de meninos e meninas com esse mundo, constitui-se dos seguintes elementos: "criatividade, risco, paixão e empatia" (MAJKOWSKI, 2015). Percebemos, claramente, que nenhuma dessas "noções 
elementares" baseia-se num saber econômico ou relacionado à gestão de empresas. Pelo contrário, estamos frente a características comportamentais e subjetivas, consagradas pelo modelo de conduta empreendedor. Como defende Angenot (2010, p. 43, tradução nossa), a hegemonia se apresenta como uma temática, que expressa conhecimentos e interesses vinculados a objetos "[...] cuja existência e consistência não parecem oferecer dúvidas, já que o mundo inteiro fala deles".

Kylee, em sua participação no Fórum da Liberdade no Brasil, também chamou a atenção da imprensa de nosso país. Em entrevistas para diversos veículos de comunicação, a garota norte-americana aprofundou um pouco mais a sua narrativa de vida. Em entrevista ao jornal Zero Hora (MARTINI, 2015), por exemplo, ela conta que, antes de se aproximar do mundo do empreendedorismo, seu sonho era o de "ser uma princesa"; porém, ao concluir que os EUA funcionam a partir de uma democracia, percebeu que esse sonho estava fadado ao fracasso. Isso a leva a afirmar, com apenas sete anos de idade, que gostaria, então, de "ser uma CEO" quando crescesse. Neste salto, de princesa a CEO, vemos a passagem de um desejo infantil marcado por um estigma patriarcal e influenciado por velhas fábulas para uma ambição condizente com o espírito de nosso tempo, em que o papel mágico está associado não mais a figuras dos contos de fadas, mas sim aos inovadores, sonhadores, também conhecidos como empreendedores.

Kylee também faz questão de adotar uma postura questionadora em relação a alguns paradigmas. Ela diz que duas perguntas guiam sua jornada empreendedora desde o início: "Por que crianças não possuem as mesmas oportunidades de abrir novos negócios como os adultos têm?" e "Por que precisamos ficar presos por trás dessas fronteiras de quantos anos temos?" (MAJKOWSKI, 2015). Essas duas indagações podem até remeter, em um primeiro momento, a uma discussão mais profunda sobre os Direitos da Criança, mais especificamente à reivindicação de dar às crianças voz ativa em todos os assuntos relacionados a elas (BUCKINGHAM, 2007). Porém, no plano discursivo, percebemos que o objetivo das perguntas de Kylee não é esse. 0 que ela busca alcançar com tais dilemas está meramente relacionado à dimensão pragmática do empreendedorismo, pleiteando a entrada de crianças no mercado de trabalho desde a tenra infância, pois elas estariam, dessa maneira, sendo treinadas e disciplinadas para sobreviver no mundo de hoje - considerado dos adultos.

Antes de finalizar sua apresentação, Kylee declara que "é um direito de nascença ser criativo e assumir riscos. E qualquer um que pensar de outra maneira não deve ter fé na 
próxima geração" (MAJKOWSKI, 2015). 0 empreendedorismo é alçado, nesse sentido, a um direito universal, suplantando os direitos específicos da criança. Além disso, quando diz que qualquer pessoa que pensar diferente dela não tem "fé na próxima geração", Kylee universaliza um projeto de futuro e impõe-no de forma imperativa, afirmando-o como monocultura empreendedora (CASAQUI, 2017). Novamente, vemos que o discurso ignora quaisquer barreiras econômicas, individuais, sociais ou etárias para tal prática, principalmente quando a palestrante diz: "Qualquer criança pode fazer isso [...]. Então, esqueça o que os outros dizem sobre você, encontre sua paixão e vá fazê-la. Porque você pode!" (MAJKOWSKI, 2015). A responsabilidade do sucesso e da felicidade é atribuída ao indivíduo, mesmo no que se refere à infância.

\section{Davizinho Braga e os segredos para a felicidade}

Também em 2015, Davizinho Braga subiu ao palco do TEDxGoiânia (Figura 3) com o objetivo de compartilhar "os segredos para a felicidade". Segundo Casaqui, as apresentações denominadas TED Talks são "[...] o grande paradigma da cultura da inspiração, nesse sentido da produção de si como narrativa inspiracional." (CASAQUI, 2017, p. 10). Trata-se de uma organização sem fins lucrativos e com alcance global que busca, a partir de suas conferências, "[...] difundir ideias, usualmente no formato de curtas e poderosas falas [...]" (TED, 2018, doc. não paginado, tradução nossa). Nesse sentido, o vídeo da palestra de Davizinho no YouTube (BRAGA, 2015) possui, em sua descrição, a justificativa do convite feito ao garoto alagoano. A organização diz que, após alcançar fama nacional no ano anterior com sua empresa List-it, a responsabilidade de Davizinho aumentou, tornando-o "referência e exemplo para crianças e jovens do Brasil". Aqui, a dimensão inspiracional de uma cultura empreendedora, que busca alcançar corações e mentes de crianças em todo o país, já toma forma.

Em seu discurso, Davizinho demonstra ter conhecimento do principal papel desempenhado por um TED Talk em nossa sociedade: o de inspirar. 0 palestrante abre sua apresentação com a seguinte fala: "Meu nome é David Braga, eu tenho 14 anos. Sou inspirador e eu sou empreendedor." (BRAGA, 2015). Ao definir-se como "inspirador", o garoto alagoano reconhece a sua trajetória de vida como um modelo de sucesso para a sua audiência, que é capaz de despertar a busca por um "eu futuro" melhor (THRASH; ELLIOT, 
Empreendedorismo, infância e celebridades: análise dos discursos do empreendedorismo para crianças

2003, p. 873), uma variante superior de si mesmo, por meio de um processo de autotransformação (CASAQUI, 2017).

Figura 3 - Davizinho Braga durante sua palestra no TedxGoiânia

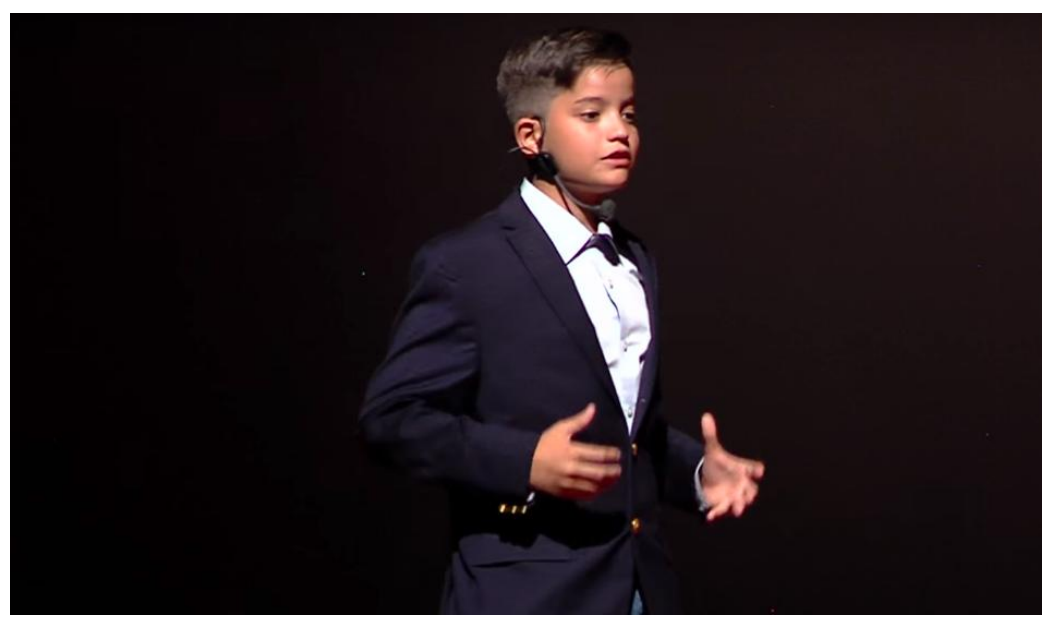

Fonte: Braga (2015).

Além disso, o próprio título da palestra - Os segredos para a felicidade - trabalha com a ideia de que precisamos formar um comportamento cronicamente feliz em nossa sociedade: um modelo de comportamento baseado na autenticidade, na autoestima e na performance de uma personalidade sociável, expansiva e enérgica, que discursivamente acaba sendo necessária para a conquista do sucesso (FREIRE FILHO, 2010). De acordo com Marín-Diaz (2012, p. 86), felicidade e sucesso são as forças motoras da autoajuda. Para a autora, ainda que seja dito que todos nós somos "eus" individuais, diferentes, e que os êxitos obtidos dependem de cada um, "[...] para todos os indivíduos são propostos os mesmos métodos, as mesmas técnicas, as mesmas qualidades e até as mesmas metas: felicidade e sucesso".

Dessa maneira, Davizinho conduz sua palestra de forma a compartilhar alguns segredos que poderão levar crianças, jovens e adultos ao encontro de tais metas. Ao versar sobre o tópico relacionado à vontade, o palestrante diz que "A inspiração vem dos outros; já a motivação vem de dentro de você." (BRAGA, 2015, doc. não paginado). Sua fala sintetiza o processo comunicacional que caracteriza a cultura da inspiração: os modelos culturais são inspirações vindas do meio ambiente, que, por sua vez, devem ter impacto na busca por uma espécie de empreendedor interior, de um eu autêntico que teria o ânimo, a coragem e os fundamentos para promover a transformação de si. Estamos, claramente, no âmbito da 
autoajuda, como trata Marín-Diaz (2012). “O principal empreendimento em nosso tempo é conceber a própria vida como algo a ser gerenciado, otimizado, performatizado, em compatibilidade com o cenário dinâmico, flexível e competitivo." (CASAQUI, 2016a, p. 3).

Davizinho também aborda o tema do raciocínio. Segundo ele, o cérebro humano tem acesso à criatividade infinita; no entanto, não somos capazes de utilizar nosso verdadeiro potencial ao ficarmos atrás de uma mesa "praticando trabalhos chatos e repetitivos". Para ele, "o sistema por completo" quer que acreditemos que essa é a nossa única opção, fazendo com que nos acostumemos "a aceitar tudo o que nos é proposto, seguir o fluxo sem questionar, engolir tudo o que é colocado goela abaixo" (BRAGA, 2015). 0 sistema, aqui, aparece como um obstáculo para a inovação, que deve ser destruído por um tipo de comportamento "disruptivo". Segundo CASAQUI (2016b), o termo "disrupção" é derivado da noção de destruição criativa atribuída por Joseph Schumpeter (1942) ao empreendedor clássico - em síntese, a ação inovadora desse ator social destrói o que havia anteriormente ao conceber novos produtos e novos mercados. Essa noção foi atualizada para um discurso do empreendedorismo contemporâneo, pautada por uma ideia de nova economia, que significa "[...] um despertar para novos negócios, para oportunidades de se recolocar no mercado com outra visão de suas funções [...]" (CASAQUI, 2016b, p. 13). 0 que Davizinho não leva em conta é que tal proposta de revolução disruptiva mantém-se no espectro do sistema capitalista, que paradoxalmente é posicionado, em seu discurso, no papel de vilão, de oposição à cultura empreendedora - como se fossem coisas distintas, opostas.

Ao introduzir o tema da coragem, o palestrante afirma a importância desse sentimento não apenas para empreender, mas para "mostrar resultado, pois o que importa é o resultado. Resultado é a única coisa que pode fazer as pessoas mudarem o que pensam sobre você" (BRAGA, 2015). Nessa fala, fica evidente a valorização do "culto da performance" (EHRENBERG, 2010), o imperativo que enaltece o alcance do máximo desempenho em todas as atividades do nosso dia a dia, sejam elas no mundo do trabalho ou no campo pessoal. Para Ehrenberg (2010, p. 18), o esporte transcendeu o âmbito das arenas, dos ginásios e das quadras para se tornar um "[...] sistema de condutas de si que consiste em implicar o indivíduo na formação de sua autonomia e de sua responsabilidade". Freire Filho (2012, p. 43), por sua vez, ressalta que o culto da performance "[...] aponta para um devir atlético e empresarial da sociedade, um processo de conversão aos valores supremos da concorrência e da conquista". Ou seja, não há lugar nessa cultura para alguém com baixo desempenho, uma vez que nossos resultados, nossa eficaz gestão de nós mesmos, são 
sinônimos de quem somos. Precisamos bater todas as nossas metas e buscar superar nossos próprios recordes incessantemente. A fala de Davizinho propaga justamente esse imperativo da sociedade empreendedora.

Partindo para o ato final de sua palestra, o garoto alagoano começa a discursar sobre os sonhos. Para introduzir o tema, ele diz que, todos os dias, quando acorda, pensa em duas coisas: "A primeira é que eu não consegui realizar todos os meus sonhos que eu queria ter realizado ontem [...]”; a segunda é “[...] que, nessa noite, eu tive vários sonhos novos [...]”. De acordo com sua fala, é esse fluxo que o faz trabalhar "feito louco" para poder realizar tudo o que almeja (BRAGA, 2015). É interessante observar como, nesse discurso, a palavra "sonho" perde totalmente seu significado original. Bergson (2004, p. 93) afirma que este termo é extremamente complexo, suscitando impasses em diversos âmbitos do conhecimento: “[...] alguns psicológicos, outros fisiológicos e mesmo metafísicos [...]". O sonho possui sua própria lógica de organização, que não é sinônimo do pensamento inovador enquadrado no modo de produção capitalista ou derivado de uma gestão eficiente das emoções. No discurso de Davizinho, no entanto, esse elemento tão complexo da psique humana ganha ares puramente mercadológicos, como se o sonho fosse apenas o precursor de processos criativos para a elaboração de novos projetos empreendedores. Seus enunciados simultaneamente são identificados com seu enunciador, sugerindo algo muito particular e até metafísico, e correspondem aos ideologemas consagrados pela cultura empreendedora, a elementos pré-construídos de suas cadeias discursivas. 0 sonho da infância, nesse ponto, não escapa ao horizonte do que é pensável em sua época, do que é imaginável na perspectiva pragmática da sociedade neoliberal.

\section{Considerações finais}

Vistos em perspectiva ampla, tanto as Aventuras da Bel quanto as palestras de Kylee e Davizinho, reiteram o sistema de ideias que alimenta a cultura empreendedora e, por extensão, o capitalismo de nosso tempo, ao passo que dão alguns tons específicos a esse quadro quando incluem a infância. Nesse cenário, a criança é construída como agente produtor do futuro, posicionada como lugar de investimento dessa sociedade ideal, em que a liberdade, a autonomia, o sonho, os desejos, tudo isso e algo mais podem ser sintetizados em um termo: empreender. Empreender o próprio sucesso e a sua felicidade, eis a mensagem que atravessa os discursos aqui analisados; discursos voltados à construção da 
criança nos moldes de uma cultura maker, de uma aura de nova economia e que buscam promover o engajamento de novos quadros no sistema capitalista.

Como discutem Boltanski e Chiapello (2009), a noção de engajamento está associada diretamente às lógicas de justificação do capitalismo, do "espírito" como retórica que se renova ciclicamente para atrair corações e mentes. Na contemporaneidade, quando o empreendedor é o modelo de conduta ideal, o fenômeno da emergência de crianças empreendedoras como celebridades com milhões de seguidores é explicado por esse papel estratégico de inspirar novos quadros desde a tenra idade. Aspectos lúdicos e discursos racionalizantes combinam-se por meio de uma estética própria, que é a linguagem voltada à infância. Tanto a estética da história em quadrinhos quanto a visualidade de crianças célebres e conectadas a amplas redes a defender os preceitos da cultura empreendedora são sinais desse desejo de engajamento, de adequação das novas gerações a um modelo de sociedade que é unificado, que não permite pluralidades além daquelas previstas dentro do próprio sistema capitalista. Pode-se ser inovador, resiliente, empreendedor de diversas formas, desde que haja uma performance de impacto, disrupção, resultados.

A diversidade dos modos de ser criança, marcados historicamente, culturalmente e socialmente, é sobreposta pelo modo de ser empreendedor quando observamos esses discursos. Trata-se de um modelo único para uma sociedade que ambiciona construir o futuro; este modelo é fortemente sustentado por um mercado de ideias e por práticas de consumo, ações pedagógicas e a comunicação. Sem que possamos concluir algo sobre os possíveis impactos desse projeto de sociedade empreendedora, o que escaparia à abordagem e ao alcance desse estudo, deixamos em aberto algumas questões para debates futuros: afinal, é possível afirmar que o futuro da infância passa necessariamente pela cultura empreendedora, ou há alternativas a esse modelo? A pergunta "o que você vai ser quando crescer" será obrigatoriamente respondida com o acompanhamento do termo "empreendedor"?

\section{Referências}

ANGENOT, Marc. El discurso social: los limites históricos de lo pensable y lo decible. Buenos Aires: Siglo XXI, 2010.

BERGSON, Henri. O sonho. Trans/Form/Ação, Marília, v. 27, n. 1, p. 93-109, 2004. 
BOLTANSKI, Luc; CHIAPELLO, Ève. O novo espírito do capitalismo. São Paulo: Martins Fontes, 2009.

BRAGA, Davizinho. Os segredos para a felicidade. In: TEDxGOIÂNIA, 2015, Goiânia. [TEDxTalks]. 2015. Disponível em: <https://www.youtube.com/watch?v=CouZKzSl3B4>. Acesso em: 13 set. 2018.

BUCKINGHAM, David. Crescer na era das mídias eletrônicas. São Paulo: Loyola, 2007.

BUONANNO, Milly. Histórias de vida exemplares. Biografias. MATRIZes, São Paulo, v. 5, n. 1, p. 63-84, 2011.

CASAQUI, Vander. Abordagem crítica da cultura da inspiração: produção de narrativas e o ideário da sociedade empreendedora. E-Compós, Brasília, v. 20, n. 2, p. 1-18, 2017.

CASAQUI, Vander. A inspiração como forma comunicacional do capitalismo "cool". In: CONGRESSO BRASILEIRO DE CIÊNCIAS DA COMUNICAÇÃO, 39., 2016, São Paulo. Anais... São Paulo: Intercom, 2016a.

CASAQUI, Vander. Esboços e projetos da sociedade empreendedora: mundo conexionista, sociabilidade e consumo. Revista Famecos, Porto Alegre, v. 23, n. 3, 2016b.

COSTA, Alessandra de Sá Mello da; SARAIVA, Luiz Alex Silva. O consenso, o exemplo e a inexorabilidade: discursos hegemônicos acerca do empreendedorismo como mecanismo de reprodução do capital. In: ENCONTRO DA ANPAD, 35., 2011, Rio de Janeiro. [Trabalhos apresentados]. Rio de Janeiro: ANPAD, 2011. Disponível em:

<http://www.anpad.org.br/admin/pdf/EOR695.pdf>. Acesso em: 16 nov. 2017.

DARDOT, Pierre; LAVAL, Christian. A nova razão do mundo: ensaio sobre a sociedade neoliberal. São Paulo: Boitempo, 2016.

EHRENBERG, Alain. 0 culto da performance: da aventura empreendedora à depressão nervosa. Aparecida: Idéias \& Letras, 2010.

FRANÇA, Vera. Celebridades: identificação, idealização ou consumo? In: FRANÇA, Vera et al. Celebridades no século XXI: transformações no estatuto da fama. Porto Alegre: Sulina, 2014.

FREIRE FILHO, João. A nova mitologia esportiva e a busca da alta performance.

Comunicação \& Cultura, Lisboa, n. 13, p. 39-52, 2012.

FREIRE FILHO, João (Org.). Ser feliz hoje: reflexões sobre o imperativo da felicidade. Rio de Janeiro: Ed. FGV, 2010.

GIDDENS, Anthony. Modernidade e identidade. Rio de Janeiro: Zahar, 2002.

HOLLANDER, Paul. A cultura da celebridade Americana, a modernidade e a decadência. In: TORRES, Eduardo; ZÚQUETE, João Pedro (Org.). A vida como um filme: fama e celebridade no séc. XXI. Alfragide: Texto, 2011. p. 61-80. 
MACEDO, Mônica Medeiros Kother; FALCÃO, Carolina Neumann de Barros. A escuta na psicanálise e a psicanálise da escuta. Psychê, São Paulo, v. 9, n. 15, p. 65-76, 2005.

MAJKOWSKI, Kylee. [Apresentação]. In: FÓRUM DA LIBERDADE, 28. 2015, Porto Alegre. Painel “Empreendedorismo". 2015. Disponível em:

<https://www.youtube.com/watch?v=xIg4qRGFKKQ>. Acesso em: 13 set. 2018.

MARÍN-DIAZ, Dora Lilia. Autoajuda e educação: uma genealogia das antropotécnicas contemporâneas. 2012. Tese (Doutorado em Educação) - Programa de Pós-Graduação em Educação, Universidade Federal do Rio Grande do Sul, Porto Alegre, 2012.

MARTINI, Felipe. Conheça Kylee Majkowski, a CEO mais jovem do mundo. Zero Hora, Porto Alegre, 13 abr. 2015. Disponível em:

<https://gauchazh.clicrbs.com.br/geral/noticia/2015/04/video-conheca-kylee-majkowskia-ceo-mais-jovem-do-mundo-4739034.html>. Acesso em: 13 set. 2017.

PESCE, Bel. Aventuras da Bel Pesce. São Paulo: Companhia Editora Nacional, 2015.

Disponível em: <http://www.aventurasdabel.com.br/hq/1>. Acesso em: 13 set. 2018.

PESCE, Bel. [Apresentação da obra Aventuras da Bel Pesce]. [2015?]. Disponível em: $<$ http://www.aventurasdabel.com.br/>. Acesso em: 13 set. 2018.

POSTMAN, Neil. 0 desaparecimento da infância. Rio de Janeiro: Graphia, 2012.

PRADO, José Luiz Aidar. Política da imagem na era da convocação. Significação, São Paulo, v. 39, n. 37, p. 167-187, 2012.

SAFATLE, Vladimir. 0 circuito dos afetos. São Paulo: Cosac Naify, 2015.

SCHUMPETER, Joseph. Capitalism, socialism, and democracy. New York: Harper \& Bros, 1942.

TED. Our organization. [2018?]. Disponível em: <https://www.ted.com/about/ourorganization>. Acesso em: 13 set. 2018.

THRASH, Todd M.; ELLIOT, Andrew J. Inspiration as a psychological construct. Journal of Personality and Social Psychology, Washington, v. 84, n. 4, p. 871-889, 2003.

Entrepreneurship, childhood and celebrities:

discourse analysis of entrepreneurship for children

\author{
Abstract \\ The theme of this paper is the entrepreneurial culture, which \\ corresponds to a process beyond economic activity: it refers to
}


social practices, behavioral profiles, moral prescriptions and the market of ideas around the entrepreneur as a paradigmatic model of our time. In this spectrum, we interrelated entrepreneurship with two other themes: childhood and celebrities, based on the discourse analysis of entrepreneurship aimed at children. The theoretical framework that organizes our reflection is based on Dardot and Laval's thesis on neoliberal society; Boltanski and Chiapello's new spirit of capitalism's concept; on fundamental works that reflects about childhood and celebrities, among others. The corpus analysis methodology is based on social discourse's theoretical-methodological proposal by Angenot.

\section{Keywords}

Communication. Entrepreneurial culture. Childhood. Celebrities.

Discourse.

Recebido em 16/11/2017

Aceito em 20/03/2018 